\title{
Investigating Current Status of English for Academic Purposes (EAP) in Iran; Revisiting ESP Specificity Continuum
}

\author{
Marjan Vosoughi (Corresponding author) \\ English Department, Sabzevar Branch, Islamic Azad University, Sabzevar, Iran \\ E-mail: Vosoughee@iaus.ac.ir \\ Ebrahim Davoudi Sharifabad \\ English Department, Bojnourd Branch, Islamic Azad University, Bojnourd, Iran \\ E-mail: davoudiebrahim@gmail.com \\ Shohreh Raftari \\ English Department, Kerman Branch, Islamic Azad University, Kerman, Iran \\ E-mail: raftari2004@yahoo.com
}

Received: 15-01-2013

Accepted: 16-03-2013

Published: 01-05-2013

doi:10.7575/aiac.ijalel.v.2n.3p.54

URL: http://dx.doi.org/10.7575/aiac.ijalel.v.2n.3p.54

\begin{abstract}
The EAP textbooks which are currently taught in Iranian universities don't seem to satisfy the necessary requirements current in new enquires of EAP research. An EAP book sample from SAMT ${ }^{1}$ publications for the students of medicine was chosen for a critical analysis on three criteria including: evaluating the objectives, reviewing the content, and evaluating the overall structure. The exploratory reviews showed that there must be major changes in EAP for medical students of SAMT to meet the specific needs of the target group above. In this article, the general status of ESP material development approaches is also depicted diachronically in order to evaluate the present situation in Iran against appropriate recent approaches towards EAP material development in the world. Recommended implications of some kind are presented throughout the various parts of the present survey.
\end{abstract}

Keywords: EAP materials, English for medical purposes (EMP), specificity continuum, material development

\section{Introduction}

English for Academic Purposes (EAP) as a sub-division of English for Specific Purposes (ESP) is regarded as a movement towards satisfying the specified needs of academic language learning groups. Although a variety of programs and gatherings have been developed for improving the current status of EAP in Iran, in effect little systematic research has been really investigated on the nature of the problems that learners might face in the whole process of trying to become active academic language users. The problem(s) might be traced back to many causes, including the whole instructional objectives, teaching materials, ESP instructors, academic inadequacies which don't provide the required services, students' lack of motivation and their inefficient or poor proficiencies. In this article, the authors have tried best to focus on textbooks' qualities as possible sources of the problems in EFL settings, namely Iran.

Textbooks, as pertinent parts of the whole curriculum in ESP courses, play an important role in flourishing the objectives of such programs. (Dudley-Evans \& St. John, 1998) Here, the authors have tried to critically evaluate an EAP instructional material entitled as ' English for Medicine Students I' (ESM I) from SAMT publications which is taught to the students of medical sciences at Iranian academic settings. Thus, this study was an attempt to answer the following three questions:

1. What are the general approaches of ESP material designers in Iran?

2. What are the weak areas of SAMP publications in EAP for medical students?

3. To what extent are the EAP goals for medical schools specific?

Before passing any value judgments, it seems essential first to briefly examine the present and the past situation concerning SAMT publications for ESP in Iran.

\section{SAMT: A historical background}

In order to improve the Iranian students' English proficiency after the Islamic Revolution of Iran, SAMT Publications in Iran constituted an educational committee for foreign languages chaired by Tahereh Saffar Zadeh in 1981. This committee invited prominent English teachers from various universities and academic institutions to decide on the best channels for the Iranian students to develop their English language knowledge through considering the most recent ESP approaches at the time. Initially, this committee distributed a questionnaire among some experienced university 
professors as well as many teachers in the Ministry of Education. About $100 \%$ of the respondents had announced that Language teaching should be specialized for various university majors. This they believed could help improve the technical academic abilities among the Iranian university students from different disciplines. Along the same lines, 100 $\%$ of the respondents had asserted that English should be the first chosen foreign language, $54 \%$ had chosen French, German was estimated $46 \%$, Arabic $27 \%$ and the rest $5 \%$ was devoted to other languages like Russian. Among the suggested skills, writing and speaking had the third and fourth ranks after reading and listening.

Considering the results statistically and going through many needs analysis processes, three stages of learning for the Iranian students were proposed. At the first stage, preliminary, basic English, entailing a quick review of the lessons learnt at previous educational levels in high schools were emphasized in a package called pre-university book for university students. At the second stage, semi-special books were designed for the students, focusing on the students' needs to improve their reading skills. The passages taught at this stage were chosen to be mostly related to the Students' field of studies in various university majors through which students improved their technical vocabulary knowledge too. Here, various subdivisions were defined mainly including English for Engineering, Humanities, Social Sciences, Agriculture and finally Medicine. At the third stage, students had to go through quite technical specialized books in English related to their majors, through which they could try to learn many skills like locating scientific references in their university disciplines and reading highly specialized technical texts. At this stage, subject matter teachers were also supposed to be able to help the English teachers; though, in reality there is no or little collaboration between the two English and content teachers in teaching these courses.

The main objective of the current EAP programs, as Attai \& Tahririan (2003) maintained, is 'to fill in the gap between the students' general English competence and their ability to read discipline-specific texts.' (p. 65) However, quite recently, the concepts of learner autonomy, independence, and automatization have gained more momentum which is apparently missing in the current EAP book series in Iran. The first and the foremost skill has been and is still reading comprehension. The other three skills have nearly no place in situ.

At the present state of the art, the Iranian students of medicine go through 12 credit English courses, four of which are general and eight specific courses. English for students of Medicine (ESM I and II) are usually taught for ESP sources at medical universities of Iran. In ESM I, those necessary grammatical structures for enhancing the students' reading comprehension are presented. In ESM II, Many translation practices are given to the students. The rationale behind using such abundant exercises is that through familiarizing the students with Persian equivalents of English medical terminologies, students won't probably use English specialized words in their future professional settings. Exposed to such long hours through many years working the ESM materials, medicine students are most of the time at a loss when confronting English for their professional purposes. Most of them complain about huge problems not only in reading comprehension skills but also in using English for their professional purposes. Here, one source of problem among others could be mapped out as the improper materials they work on in academic settings. It is generally believed that a good course book doesn't teach but provides chances for students to learn.

Here, the authors have gone through reviewing ESM course books to find the source of the above-mentioned problems among medical practitioners. However, before touching the issue in more details, some general material development processes in EAP are chronologically presented.

\section{Approaches in Material development in EAP}

In many cases, curriculum is just considered as the content page of some course books or a list of topics to be covered during the term. A curriculum, on the other hand, has much more to do. Flowerdew and Peacock (2001) highlighted the fact that teaching and learning of EAP is a challenging task for students, teachers and curriculum designers. They categorized three vital phases of curriculum development or renewal. The first phase involved the description of the needs of the EAP students, which are conducted through a comprehensive needs analysis. The second phase was related to the actual teaching-learning process in the light of the needs set in the previous phase and the last phase was selecting the right methodology or approach in order for the EAP teachers to achieve identified objectives and overcome identified weaknesses.

Throughout the history of ELT, practitioners in the field have experienced two quite different approaches in material designing. In the first approach, language was considered a system entailing certain components including phonology, lexis and syntactic elements. Here language was presented bit by bit to the learners. This was entitled as a synthetic syllabus.

So $\mathrm{a}+\mathrm{b}+\mathrm{c}$ of language $=$ synthesize $=$ language as a whole

In the other approach, language was assumed to be a totally integrated phenomenon. All components of language and skills were manifested collectively. This was called an analytic syllabus.

So language as a whole $=$ analyze $=a+b+c$ of language.

Situational syllabuses in which materials were obtained from realistic situations then appeared. Functional syllabuses were the next trend. In fact, functional teaching served as a motive behind material development in ESP. This was because different groups of learners needed to satisfy their communicative needs with language functions. In 1985, another line of research called for activating rhetorical functions over the use of lexicon and syntactic elements. It was rooted in social anthropology and linguistic philosophy. So, speech acts were mostly focused upon. 
In 1990s, "Genre Analysis" was a dominant field. Here, a class of communicative events were recognized which shaped the schematic structure of the discourse and influenced the content and styles. At this time, the significance of the communicative purpose is clarified as the essential element of a genre.

\section{Methodology}

This paper outlines an evaluative review of SAMT publications regarding its course books for the students of medicine through a descriptive approach. The book chosen for this brief enquiry is "English for University Medicine Students I" by Didari \& ZiaHosseini, (1995). Three different criteria were chosen for the present evaluation including;

1. Objective evaluation

2. Content review and

3. Structural evaluation

Before going through the selected criteria above, a thorough overview of ESM is first represented briefly.

\subsection{Some remarks on ESM series}

ESM is among the semi-disciplined or semi-specialized English courses designed at the second stage of SAMT job described above. It involves 19 units. The table of contents does not give any hints or observable clues to the skills and sub skills of language. Each unit contains three parts namely pre-reading, reading passage, and after-reading.

In the 'pre-reading' part, there are some sub-parts including A: pronunciation, B: word-study: Definitions, C: wordstudy: Definition and exemplification and D: Grammatical points to be explained.

In part A, those relevant words to be introduced in the incoming seeded passage are given with nearly full pronunciation descriptions through phonetic symbols. In part B, some of these words are defined in English using simple terminologies.

In part C, some other words are defined along with some examples containing their use in context. Here, the new words are contextualized. In part $\mathrm{D}$, the grammatical structures used in the due passage(s) are explained through some simple examples without any terminological explanations.

Then follows part II, which brings the reading passage. Afterwards, some comprehension questions involving the predictable design for all lessons as True/False, filling the slot and then some questions to be answered orally. In part III, some exercises have been given through four sections. Section 1 contains vocabulary exercises. Section 2 involves grammatical exercises and section 3 deals with reading comprehension exercises involving an additional passage and there is a final section on translation practice.

\subsection{Objective evaluation}

Yule ( as cited in Zohrabi, 2005: 40 ) asserts: " Establishing what the learners need to know involves determining what the learners' aims are in learning the language (for example, getting a job as a sales clerk, or earning a BA in engineering). Robinson (1991:5) wrote, "We are teaching English not for specific purposes but for specified people'. This refers to what the learners will do with language when the course finishes. This is the goal-oriented definition of the learners' needs.

To reach the goals, previous stockholders like Hutchinson and Waters (1987: 14) emphasized on an understanding of the processes of language learning .i.e., they believed the concerns in ESP aren't with language use, but with language learning itself. Because ' we can't simply assume that describing and exemplifying what people do with language will enable them to learn it. ' Todd (2003:147-156) reported by Gholamy et al., (2005: 193) believes that teaching EAP suffers from too much emphasis on content. He recommends a more balanced approach that gives importance to both rules and procedures and in course designing. So, a course is deemed well if it considers both the ends and means used to achieve those ends. Bhatia (2008) has critically touched on such issues as purpose identification for context- specific affairs defined for ESP clients in the 21st century. Recent critical genre theories illustrating, in particular, interdiscursivity studies in (Bhatia, 2010) within multi-perspective genre analysis (Bhatia, 2004) has been put forward to meet the needs. Browne (2011) on the other hand elaborates on a challenge faced by EAP course designers to take into account the high school-level student to a position defined as 'freshman ' or 'sophomore' for which higher-level skills, such as technical reading, writing, and presentation skills. So the challenge on objective specification here shows itself as to which route to take? The traditional ESP designers went for fulfilling context-specific needs for their stockholders while the more recent course designers go for a continuum depicting specificity levels ie, ESP materials spell out that needs shouldn't be narrowly defined so that they are completely distinct from general English materials. For Iranian EFL contexts, Farhady (1994) had already suggested accommodating all the complexities of specificity in ESP through a hierarchical-international model along a continuum with macro- specification at one end and microspecification at the other end.

In ESM series, the goals have not been specified clearly. What a graduate student in medicine uses English for might be more than just reading English encyclopedias and reviewing text materials. We already know that a doctor might also need English for communication purposes like taking his patients' personal or social histories. He might need to learn how of study skills for web surveying including skimming, scanning, note takings, reading English encyclopedias, reviewing text materials in major databases like Cochrane and Pub Med, Oral presentation skills in English like listening to lectures, taking notes along with written communication skills such as understanding common structures of 
argumentation, supporting opinions with evidence, and representing abstract concepts visually using figures and tables among many others.

In fact, concerning the learning purposes in ESM what is obviously absent is the curriculum designers' full attention to the learners' role in decision-making processes. In recent years, the data provided by the learners are focused upon through port- folio syllabus designations. Student-generated materials are currently much welcomed by the ELT scholars. Such needs analyses need to be collected through both learner analysis as well as task analysis processes. This subjective data through the learners' participation includes information on why the learner has undertaken to learn a second language, and the classroom tasks and activities that the learners prefer. Within ESP approaches, such needs analyses by the curriculum designers have already been taken into account, but what seems pertinent in this regard is the emphasis needed to be put on the ongoing active processes in the whole material development procedures through lots of formative assessments. Along similar lines, Munby cited by Nunan (1978: 19) provided a very complex model containing nine elements including, participants, purposive domain, setting, interaction, instrumentality, dialect, target level, communicative event, and communicative key. By this last element Munby meant that the syllabus designers need to specify the interpersonal attitudes and tones the learners will be required to master. All such information gathering processes are nearly lost in all EAP course books in Iran, ESM no exception.

The underlying reason for such inadequacies in ESM series seem to be the bitter fact that ESP courses in Iran are not usually taken seriously by the learners. In most cases they don't have a clear picture of the nature or objectives of the courses and that's why the university students do not usually expect to be able to improve English through these courses. Such lack of motivation on the part of the learners distracts their main immediate attention to the specific goals they must take heed of in their fields of studies. For sure, other issues such as ESP methodology, teacher qualifications, and testing considerations among many others can also influence this milieu accordingly. Thus, recapping the ESP specificity continuum, course designers must first clarify their country's intermittent positions on various levels on the continuum in order not to lose the track. (Fig. 1)

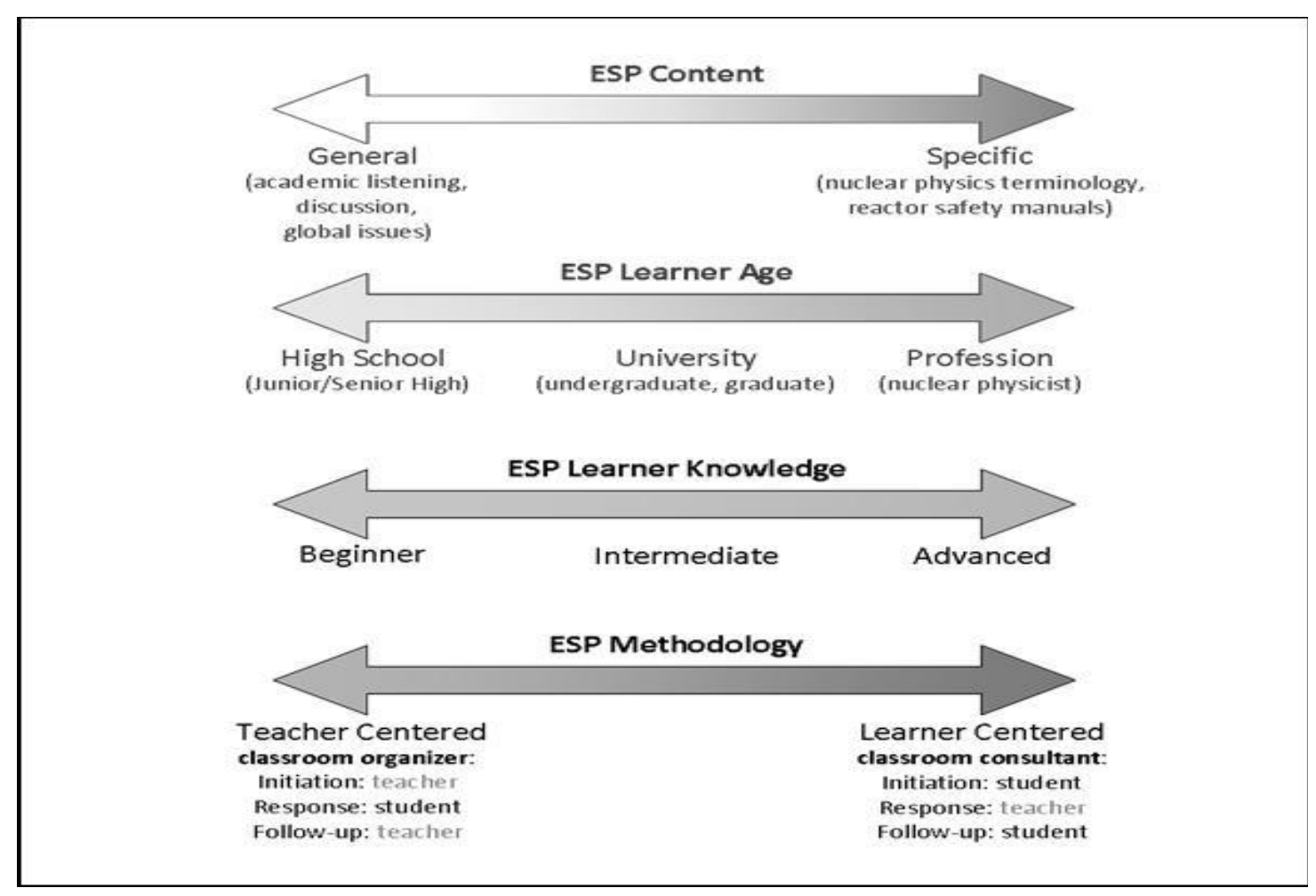

Figure 1. The ESP Specificity Continuum

A closer look into the continuum reveals that all four levels including ESP content, learner age, learner knowledge, and methodology take their directions from specific points at two extreme ends all through intermediate points for which we have to initially define our objectives. At one end of the first continuum, ESP content, academic skills including listening note-taking skills are specified then sub objectives will be worked on based on the specific purposes the ESP clients are taking the courses. Those sub- objectives might then include using a suggested note-taking method, summarizing spoken texts and lectures, distinguishing main ideas, differentiating important and irrelevant information, etc. Then at the other end of the continuum, more specific content are prescribed like nuclear physics terminology or reactor safety manuals for a major like Nucleonics. At one end of the second continuum should be a desire for an ESP course designer to measure ESP learner age, to specify in advance for which clients we are going to prepare lessons. In ESM books and publications in Iran, there needs to be such a consideration in this regard. The students of medicine in Iran go through 12 English courses, four of which are general and eight specific courses. ESM I and II are usually 
taught for freshmen and sophomore medical students at medical universities; however, the only difference which is seemingly felt is in terms of content specificity. No such age differences of any kind have been cared for in advance in ESM series as the students mature during the 12 courses. Overall, there needs to be an overall reconsideration of the goals in EAP for medical students according to the levels on the ESP Specificity Continuum as Farhady (1994) had rightly sought for. He felt the need for Iranian ESP in order to accommodate all the complexities of specificity in ESP through a hierarchical-international model along a continuum with macro- specification at one end and microspecification at the other end thus taking into account all possible conditions illuminating the specific objectives; however after going through a decade or so, little or no changes have been made to the current situation in Iran.

\subsection{Reviewing the content}

Concerning the relevant content in each unit, what is obviously missing is the fact that the communicative approaches have been entirely forgotten and the whole unit revolves more around traditional structurally- based methods of planning. At the first sight when one is encountered with Pre-reading section, it brings to the mind the fact that it is perhaps intended to discuss some of the relevant points within the texts too; however, quite to the contrary, it has just introduced some words, their definition, and then the grammatical structures brought in the passage. The texts all suit a sentence level analysis vs. skill-centered interpretive strategies which enable the students to elicit meaning from the text. As far as methodological aspects are concerned, this is by no means in line with training independent autonomous learners.

In EFL situation like Iran, the uni-skill reading approaches are precisely followed by curriculum designers. Concerning reading skills in ESM by SAMT publications, in almost no lesson the material designers have taken heed of other still pertinent sub-skills including matching headlines with paragraphs, identifying where to find relevant information, skimming to find out the text organization, note-taking, summarizing through completion tasks, etc. For medical students, those essential reading skills might also involve surveying medical texts, finding existing systematic reviews in health care databases, scanning primary studies in medicine, summarizing information from different sources for their research purposes, synthesizing study results in various medical fields, appraising proper published materials as well as others. A close introspection into each lesson simply reveals that in ESM assembly-line text-based lessons are repeated one after the other, only the texts' themes are medical without any consideration for medicinal needs of a would-be doctor in future. Apart from reading skills, a medical student might also need English for his/her future status as a medical practitioner or resident commentator communicating medical messages at international levels, expressing opinions and giving support to those issued opinions, commenting on a given opinion by his/her medical partner outside the region or even challenging a given opinion, illustrating and explaining various pharmaceutical points, interrupting and dealing with interruptions and inviting other medical contributors at international planes to join his/ her research team. Maybe it would be better for the course designers to cater for integrative skill presentation techniques like Brown's (2004) framework. Accordingly each lesson will go for a simultaneous skill work and practice like the following:

_ a pre-reading discussion of the topic to activate schemata;

- listening to a lecture or a serious of information statements about the topic of a passage to be read;

_ a focus on a certain reading strategy, say, scanning; and

_ writing a paragraph of a section of the reading passage

Apart from skill integration at academic levels, If we want to know the EAP learners' realistic needs in the modern era, esp., medical students, We can visualize such needs as various socio-cultural aspects of academic lectures on various fields in English, a variety of discoursal features of academic lectures and written discourse, a range of strategy training practices, diverse academic literacy skills, knowing research skills such as: a) learning to use different sources for research, c) identifying reliable sources for research, d) evaluating texts and sources, quoting, e) paraphrasing, and f) summarizing all through the medium of English as a lingua franca which is again missing in many EAP series of books, ESM no exception.

As to linguistic elements, lexis and structure, in part I. of ESM books, there is a subpart C in which the words have been exemplified. That seems reasonable but some of the given contexts are not in fact authentic. It would be better if the words were relevant to the subject fields of the students. For instance, the word 'contact' in the first lesson of the ESM book has been exemplified as:

* The men were digging a deep hole when they came into contact with an electric power line. Here the word 'contact' is not at all related semantically to its meaning in the given text in lesson one on 'common cold'. It is rather closer to the word "found" rather than the state of touching as intended and relevant to diseases.

In part $\mathrm{D}$, the grammatical structures are explained followed by some grammar exercises. As a matter of fact, the ESP designers have isolated language into its parts as in traditional analytic syllabuses. A quite mechanical way of introducing the language elements are followed in each lesson. The variety of grammar exercises isn't sufficient. All lessons follow the same routines; combining and completing the given sentences without clarifying the relevance of the structures to their use. Such traditional focus on grammar and vocabulary approaches in ESP course books in fact abstract academic literacy from social context. ( Hyland \& Hamp-Lyons, 2002, as cited in Melles, 2004:3). 
Since English in Iran is not considered in fact a Lingua Franca, all the efforts towards learning it would be restricted more to educational or academic centers and if any just for reading purposes. Notional- functional syllabi and taskbased (TBLT) language teaching models have nearly no place.

\subsection{Evaluating the overall structure}

If we believe students' motivation and interest should be catered for, a close look at not only ESM but nearly all ESP course books shows that they are at a loss in this regard. Various exercises of similar trends are given for structures only. If we pay close attention, we can clearly observe voluminous texts with superfluous, wordy and boring lessons. An example is (lesson 3, ESM I.) It goes without saying that as mentioned above following pluralistic approaches through which no single method of presentation or no single exercise can easily satisfy all learners' cognitive styles and strategies would be a must. Concerning activity types, it seems pertinent to include all three -mechanical, meaningful, and communicative- kinds in order to suit all learners' cognitive styles. The uniformity of one single pattern for all lessons means entailing a strict nonflexible organization and burden on learners. In ESM, the same observed plan is followed for all lessons. It seems that one of the most important assumptions in the material development and curriculum design encounters here is missing. It's nothing but 'pluralism' through which a variety of tasks, activities and drills are cared for in order to cater for individual differences of heterogeneous students.

In this series of books, there is no place for non-linear information of any kind such as graphs, charts and/or prosodic features for increasing understanding. This aspect might otherwise encourage some well-motivated students. All in all, cosmetic orientation of not only medicine series but also all ESP books from SAMT needs revisions of some kind. They all lack sufficient tables, graphs, cartoons and impressive posters or pictures.

Based on the upcoming discussion, the general designation for all lessons apparently is congruent with those traditional synthetic syllabus designs centering on such elements of words, grammatical structures, notions and functions separately.

\section{Discussion}

In this article, the authors tried to consider one of the EAP course books by SAMT publications for medical students titled (ESM) in Iran. Some pertinent factors like the aim of ESP books, their contents and lesson formats were briefly evaluated. In modern student-centered instruction approaches, the appropriateness of materials includes student comfort and familiarity with the material, language level, interest, and relevance. However, it sometimes happens that teachers are obliged to use the same materials and the same textbooks reminding one of assembly-line approaches repeatedly over and over again. If the due course books are properly designed and involve a sufficient basis of flexibility for rearrangement, it would better suit the students' needs, abilities, and interests within the course. It goes without saying that motivating the students with variety, relevance and fun can change them to active participants and encourage them to take initiative and assume responsibility for their own learning. Well-organized authentic materials are just one means towards reaching the goals. Henry Sweet (as cited in Gilmore, 2007) was one of the first advocates of using authentic materials. As he asserts 'natural texts do justice to every feature of the language' while artificial contrived materials comprise 'repetition of certain grammatical constructions, certain elements of the vocabulary, certain combinations of words to the almost total exclusion of others which are equally, or perhaps even more essential'. Focus on communication, social skills, process-oriented methodologies and training proficient bilingual teachers are also significant to a great extent in order to prevent spoon feeding teaching methodologies now current in many Iranian institutions. Current EAP in Iran must be based on ' study skills models'. Training Academic literacy is another missing link in the present situation. It's been left untouched in the EAP education in Iran thus leading to a mismatch between theory and practice. It's true that the first and the foremost skill taught in EAP SAMT books is and should be READING. However, the lessons haven't been even designed for activating reading skills. They all contain text-based lessons. Apparently, the recommended micro-skills have been totally forgotten like the following:

\section{Scanning}

2. Skimming

3. Guessing meaning from context

4. Predicting the content

5. Reading for main ideas

6. Learning word clusters

7. Analyzing paragraph organization

8. Examining graphical info.

9. Reading for details

10. Note taking

11. Activating schemata

12. Critical reading (learners' reassessment of the truth and logic of the text content

13. Collocations, ... 
Unfortunately, the case for most of EFL professors at tertiary level is not to meet specific needs of their students. They just follow an off-the-shelf courses or course books. No interaction of any kind is accomplished between the stock shareholders, policy makers, teachers and students. In a study by Askari (2005: 127), an investigation was done over a period of three semesters from 2002 to 2004 among a group of medical university students in Iran. The intention was exploring the students' learning needs and expectations, their encountered difficulties, and their overall assessment of ESP courses for them. In terms of students' participation in class, it was found $70 \%$ were shy to talk to their friends and nearly $90 \%$ had almost no chance to speak it outside class. Then the students were asked to prioritize the importance of different skills of learning in certain areas. Professional (ESP) reading texts were a priority for both the first and secondyear students of medicine. They also welcomed presenting medical articles orally in ESP courses. Oral fluency was reported the most problematic area. In terms of difficulty ranking, English for medical purposes ( EMP) vocabulary, reading, and tenses had been reported as the most difficult for the students.

\section{Summary and Conclusion}

In a nutshell, the Iranian curriculum designers and policy makers are recommended to move from transitional teaching paradigms towards new constructivist paradigms, forgetting uni-skill approaches (just reading) and move towards multi-skill approaches. When such changes are made from above, we can be more hopeful that the other lower educational hierarchies for EAP triangle are fixed permanently; such changes can bridge in the gap between the theoretical rationale of EAP in Iran on the one hand and ESP material designers on the other, thus provoking pluralism in task designing among EAP instructors, inspiring more face validity which is necessary for learner-centered educational settings, and finally inciting more efficient needs analysis on the part of curriculum designers.

Overall, maybe the Iranian curriculum designers can take the following initial steps in order to fulfill the learners' real needs.

1. Incorporating both print and non-print materials; e-books, digital versions, multimedia,...

2. Paying more attention to learner-centered approaches in course designing

3. Going through more efficient needs analysis

4. Training proficient bilingual teachers

5. Forgetting assembly-line approaches

6. Strategy training,

7. Attention to text rhetorical organizations,

8. Whole person approaches,

9. Skill- based integration

10. Including more self- assessment activities

\section{References:}

Askar Anari, (2005). J. "Issues of learning EMP at university: An analysis of students' perspectives", Proceedings of the first national ESP/EAP conference, Vol (II) (pp. 127-143). Tehran, Iran: SAMT Publications.

Attai \& Tahririan, M.R. Attai and M. H. Tahririan, (2003). "Assesment of the status of ESP in the current higher educational systems", Proceedings of LSP; Communication, Culture, and Knowledge Conference, University of Surrey, Guilford, UK.

Attai and Muhammad Zadeh, M.R. Atai and A. Mohammadzadeh, (2007). "A needs analysis study of Iranian graduate ESAP students of humanities: a triangulated perspective, Proceedings of the 6th International AELFE Conference: Teaching and Learning LSP: Blurring the Boundaries", ISCAL, Lisboa, Portugal .

Bhatia, Vijay. K. (2004). Worlds of Discourse: A genre-based view, London, Continuum.

Bhatia, Vijay K., (2008). „Genre Analysis, ESP and Professional Practice“, English for Specific Purposes, 27, 161-74.

Bhatia, V.K. (2010). Interdiscursivity in Professional Communication" ", Discourse and Communication, 21/1, 32-50.

Brown, H. D. (2001). Teaching by principles: An integrative approach to language pedagogy (2nd ed. (p.32). Longman.

Brown, C. (2011). Comprehending authentic video: The importance of high frequency vocabulary. Paper presented at JaltCALL 2011 Annual Conference, June 3-6, 2011. Kurume, Japan: Kurume University.

Didari, Reza., \& ZiaHosseini, M. (1997). English for the students of medicine I, Tehran: SAMT publications.

Dudley-Evans, T. and St John, M.J. (1998). Developments in English for specific purposes: a multi-disciplinary approach. Cambridge: Cambridge University Press.

Farhady, H. (1994). "On the specificity of purpose in ESP." proceedings of the 2nd conference on theoretical and applied linguistics. Tehran: Allame Tabataba'ee University.

Flowerdew, J. \& Peacock, M. (2001). The EAP curriculum: Issues, methods and challenges. In J. Flowerdew and M. Peacock (Eds.), Research perspectives on English for academic purposes (pp. 177-194). Cambridge: Cambridge University Press. 
Gholamy, J ; Mohammad Nia, Z. \& Asl Rasouli, M., (2005). " A process-oriented, Interactive EAP project on Medical English: A case report", Proceeding of the first National ESP/EAP conference, Vol. II. (pp. 186-204) Tehran, Iran: SAMT.

Gilmore, A. (2007). Authentic materials and authenticity in foreign language learning. Language Teaching, 40(2). Pp 97-119.

Hutchinson, T. \& Waters, A. (1987). English for specific purposes: A learning-centered Approach (p.14). Cambridge: CUP.

Isfahani, H., (2005). On needs assessment of physical education students. Unpublished M.A. Thesis, University of Tehran, Iran.

Melles, G. (2004). "Critical thinking in ESL for postgraduate engineers: negotiating a discipline." Retrieved from www. Esp-world.info./ articles-5/ Melbpourne.htm

Munby, J. (1978). Communicative Syllabus design. Cambridge: Cambridge University press.

Nunan, D. (1998). Syllabus Design (p.19). Oxford: oxford university press.

Robinson, P. (1991). ESP Today: A practitioner's Guide (p.5). New Jersey: Prentice Hall International.

Todd, R. W. (2003). " EAP or TEAP?" Journal of English for academic purposes, 2, (pp. 147-156).

Yurekli, A. (2012). "An Analysis of Curriculum Renewal in EAP Context", International Journal of Instruction, Vol.5, No.1

Widdowson, H.G. (Ed.) (1982). Reading and Thinking in English. Oxford: OUP.

Zohrabi, M. (2005)."Trends in ESP \& EGP", Proceeding of the first National ESP/EAP conference, Vol. II, (pp.34-50) Tehran, Iran: SAMT.

\section{Note:}

1.The centre for Studying and compiling University Books in Humanities 